\title{
Do discurso e das condicionalidades do Banco Mundial, a educação superior "emerge" terciária
}

\author{
Raquel Goulart Barreto \\ Universidade do Estado do Rio de Janeiro, Programa de Pós-Graduação em Educação
}

\section{Roberto Leher}

Universidade Federal do Rio de Janeiro, Programa de Pós-Graduação em Educação

\section{A materialidade do discurso}

A primeira parte deste artigo é estruturada a partir da análise crítica de discurso, formulada por Fairclough (2001), objetivando o discurso como prática social indissociável das demais. Não se confundindo com "atividade puramente individual ou reflexo de variáveis situacionais" (p. 90), o discurso é pensado como modo de ação que, por sua relação dialética com a estrutura social, permite "investigar as práticas discursivas como formas materiais de ideologia" (p. 116).

Sendo dialética a relação entre discurso e estrutura social, não pode ser simplificada por leituras mecanicistas ou deterministas. Fairclough (2005) sublinha que há mudanças na vida social que são, em parte, mudanças no discurso sem serem apenas discursivas, ao mesmo tempo em que há mudanças discursivas que podem não apontar para mudanças sociais, como as de motivação retórica. Portanto, adverte que evitar a redução da mudança social ao discurso é tão importante quanto reconhecer o último como um elemento ou "momento" dialético da primeira.
Visando afastar associações diretas e simplistas entre o discurso dos organismos internacionais e as políticas formuladas em nível nacional, sem mediações, este artigo está centrado no conceito de recontextualização, nos termos em que formulado por Fairclough (2006, p. 101): "um fenômeno complexo, envolvendo, para além de uma simples colonização, um processo de apropriação cujas características e resultados dependem das circunstâncias concretas dos diversos contextos". Em outras palavras, as condicionalidades impostas pelos organismos internacionais aos países "em desenvolvimento" ou "em transição" são "traduzidas e adaptadas" no enredo das formulações locais, compreendendo a dimensão material e a simbólica das disputas por hegemonia. Concretamente, a recontextualização requer a consideração histórica do bloco de poder, da correlação de forças entre as classes e do lugar do Estado na garantia dos imperativos capitalistas.

O conceito gramsciano de hegemonia permite dimensionar os movimentos de entrega e resistência dos sujeitos aos sentidos sedimentados e aos deslocamentos (ressignificações) como formas de luta pela 
legitimidade dos diferentes sentidos, já que, em meio aos sentidos possíveis, um tende a ser mais "lido", enquanto os outros podem nem ser cogitados. Em outras palavras, na perspectiva histórico-discursiva, a ideologia corresponde à hegemonia do sentido (Barreto, 2002).

Outra referência importante neste trabalho é o ensaio de Bourdieu e Wacquant (2001) acerca da "nova ordem", constituída por um novo tipo de imperialismo e expressa por uma "nova vulgata planetária". Os autores destacam-lhe a performatividade - seu poder de forjar as realidades que ela afirma descrever -, bem como elencam as palavras recorrentes e as foram banidas com o pretexto de serem impertinentes ou de se terem tornado obsoletas.

Sem dúvida, escolhas lexicais implicam mudanças nas formulações, seja por neologismos criados para dar conta de novos aspectos da realidade, seja por palavras e expressões que, já cunhadas e conhecidas, são apropriadas em diferentes discursos, contextos e matrizes conceituais. É o caso da expressão "sociedade civil" em textos recentes do Banco Mundial (doravante $\mathrm{BM})$, em sentido evidentemente diverso do conceito gramsciano. ${ }^{1}$ Entretanto, as questões discursivas não se esgotam no plano do vocabulário. Aspectos sintáticos e pragmáticos não podem ser desconsiderados em qualquer análise que pretenda abranger as relações intertextuais. Palavras e expressões podem ser investidas de sentidos diferentes em função de quem as pronuncia, a quem são dirigidas, onde e em que circunstâncias. Em resumo, os sentidos são determinados pelas múltiplas condições da sua produção: das macro-históricas às circunstanciais.

De um lado, é preciso reconhecer que as palavras, em si, não são suficientes para a abordagem das múltiplas dimensões das lutas por hegemonia. ${ }^{2}$ De outro,

${ }^{1}$ A propósito, ver o texto Do confronto à colaboração: relações entre a sociedade civil, o governo e o Banco Mundial no Brasil (Banco Mundial, 2000).

${ }^{2}$ A produção de sentidos também não se reduz à linguagem verbal. Cada vez mais circulam textos que envolvem outros materiais semióticos. Neles, imagens e palavras articulam-se, é importante considerar a recorrência de palavraschave como possibilidades de entrada no discurso da nova ordem. A mais destacada é "emergência". Há um número sempre crescente delas, convergindo em uma mesma direção.

Ainda que a língua inglesa disponha de outra palavra (emergencies) para designar acontecimentos inesperados e perigosos que requerem ações imediatas, a presença de tantas emergências (emergences) é uma marca discursiva importante. Com elas, os processos e as relações do espaço-tempo global são representados de modo categórico, como se não fossem passíveis de contestação, como se simplesmente acontecessem, seja a partir de fatores não-humanos, inanimados (tecnologias, mercado), seja por nominalização (emergência, mudança). Faltam sujeitos e sobram "emergências" que supostamente independem deles.

Pelo exposto, a materialidade do discurso do Banco Mundial será aqui analisada a partir dos seguintes pressupostos: a agência sabe o que é melhor para o mundo e usará seu poder político-econômico para ajustá-lo a essa formatação (Barreto \& Leher, 2003). Na assimetria que constitui suas relações com os Estados nacionais, especialmente os periféricos, estabelece as condicionalidades funcionais aos interesses geopolíticos (dos países centrais) e econômicos (de suas corporações e financeiras), persuadindo o conjunto da sociedade de que, supostamente não havendo alternativas, as ações impostas não configuram escolhas, mas soluções que emergem do encaminhamento correto dos problemas.

\section{Banco Mundial: as publicações-chave, segundo o próprio ${ }^{3}$}

É importante que esta análise seja iniciada pela posição ambígua que o BM assume em relação a essas

basicamente por convergência ou divergência (Barreto, 2002), rearticulando aspectos extralingüísticos, sociais.

${ }^{3}$ São quatro, identificadas na página referente à "educação terciária (educação superior)": http://web.worldbank.org/WBSITE/EXTERNAL/TOPICS/EXTEDUCATION/0,,contentMD 
publicações. À exceção da produzida em 2000, em convênio com a Organização das Nações Unidas para a Educação, a Ciência e a Cultura (UNESCO), elas incluem notas introdutórias que imputam às equipes formuladoras a responsabilidade pelas descobertas, interpretações e conclusões. Ao mesmo tempo, é o BM que lhes atribui o estatuto de publicações-chave.

Para sustentar a discussão acerca dos movimentos empreendidos pelas referidas publicações, o esquema a seguir pretende ser elucidativo:

Esquema 1

\begin{tabular}{|c|c|c|}
\hline 1994 & Neoliberalismo & "economia de mercado" \\
\hline 2000 & Globalização & "mercado global" \\
\hline 2002 & $\begin{array}{c}\text { Economia } \\
\text { baseada no } \\
\text { conhecimento }\end{array}$ & $\begin{array}{c}\text { "mercado global da } \\
\text { informação" }\end{array}$ \\
\hline \multirow{2}{*}{2003} & $\begin{array}{c}\text { Globalização }+ \\
\text { sociedade do } \\
\text { conhecimento }\end{array}$ & $\begin{array}{c}\text { "participação na sociedade } \\
\text { civil como competência } \\
\text { na economia do } \\
\text { conhecimento" }\end{array}$ \\
\hline
\end{tabular}

\section{Tomando cada uma das publicações:}

1994 - Educação superior: as lições da experiência - um texto que se afirma centrado nas políticas e práticas para a redução da pobreza no mundo em desenvolvimento. Promove uma associação direta entre redução da pobreza e educação superior, ao mesmo tempo em que reduz esta última a treinamento, desde a foto da capa, na qual está estampado um estudante senegalês seguindo atenta e solitariamente instruções escritas para montar um aparelho. No corpo do texto, há indicações claras da reforma pretendida: "a edu-

K:20298183 menuPK:617592 pagePK:148956 piPK:216618 $\sim$ theSitePK:282386,00.html. Em ordem cronológica crescente: Educação superior: as lições da experiência (1994); Educação superior nos países em desenvolvimento: perigo e promessa (2000); Construindo sociedades do conhecimento: novos desafios para a educação terciária (2002); e Educação permanente na economia global do conhecimento: desafios para os países em desenvolvimento (2003). cação à distância e os programas de aprendizagem aberta podem aumentar, efetivamente e a baixo custo, o acesso dos grupos desprivilegiados" (p. 33). Há referências à remoção de obstáculos como "movimentos estudantis fortes e governos fracos" (p. 25), assim como ao "desenvolvimento de instituições nãouniversitárias e ao financiamento privado, visando a produzir as qualificações exigidas por uma economia de mercado" (p. 31), a exemplo do Serviço Nacional de Aprendizagem Industrial (SENAI).

Enquanto o título sugere o passado ("experiência") como a principal referência, as "lições" são remetidas ao suposto sucesso futuro prometido: cursos flexíveis e de curta duração, sob demanda. O que é posto em jogo é o futuro próximo: "A menos que sejam implementadas reformas para melhorar o desempenho da educação superior, muitos países estão destinados a entrar no século XXI despreparados para competir na economia global, em que o crescimento estará cada vez mais baseado no conhecimento técnico e científico" (p. 25). A menção a destino permite essa espécie de premonição traduzida como ameaça, palavra utilizada no documento de 2002: "esses países estarão cada vez mais vulneráveis às ameaças emergentes” (p. 13).

Três pressupostos da formulação de 1994 merecem destaque: a) a educação superior para grupos desprivilegiados deve ser substituída por treinamento de baixo custo; b) os países, incluindo os "desprivilegiados", estarão aptos a competir no mercado global; e c) se alguns países não alcançarem esse patamar, será por culpa dos próprios.

2000 - Educação superior nos países em desenvolvimento: perigo e promessa - de autoria da "forçatarefa" conveniada (BM-UNESCO). Aprofundando as "lições" anteriores, supõe a ausência de qualquer dúvida acerca da "solução" para "velhos problemas e novas realidades" (capítulo I e p. 26) ou de onde, quando e como aplicá-la. Como novas realidades, o documento identifica: a) a expansão resultante "do crescimento vertiginoso do número de alunos" (p. 19); b) a diferenciação crescente dos tipos de instituição e dos "novos fornecedores no setor" (ibidem); e c) a 
revolução que permite "acessar o conhecimento mais rapidamente e de lugares cada vez mais distantes" (p. 32).

Essas novas realidades, na medida em que são "emergentes", sugerem que o futuro chegou e poderá ter duração expandida indeterminadamente. Além disso, nenhuma delas terá poder suficiente para mudar o "destino" dos países mais pobres. Ao tratar do "investimento na produção de conhecimento", a força tarefa evoca uma lacuna que não será sequer diminuída, ao afirmar que "esta questão não é relevante para os países de renda baixa ou média baixa, cujo foco estará no desenvolvimento da capacidade de acessar e assimilar conhecimento novo" (p. 35). Em outras palavras, estão em xeque os pressupostos da publicação anterior (1994), já que o foco determinado conecta o perigo maior à promessa vazia: a que não será cumprida.

2002 - Construindo sociedades do conhecimento: novos desafios para a educação terciária - esse documento introduz o deslocamento central para a passagem: de educação superior a terciária. A rigor, o conceito já estava presente, mas a expressão não havia sido utilizada. A promessa também é deslocada para "desafio". Os países em desenvolvimento e em transição, mencionados mais de uma centena e meia de vezes, são exortados a assumir a responsabilidade pela reforma prescrita, no contexto da "construção discursiva e material da 'economia global' associada à 'baseada no conhecimento', tendo a liberalização do comércio e dos serviços como elemento central" (Fairclough, 2006, p. 73).

Além de mencionar "realidades emergentes", o documento inclui um conjunto significativo de "emergências" (resultados). Aponta tendências como "as novas demandas do mercado de trabalho e das novas tecnologias" (p. 24); "a competição entre universidades privadas emergentes" (p. 63), vista como "saudável" por favorecer "a inovação e a eficiência gerencial" (p. 69); e "um mercado internacional de educação terciária" (p. 33), todas podendo ser resumidas na "aparição de novos fornecedores" em um "ambiente educacional sem fronteiras" (p. xix). São as "forças do mercado agindo sobre a educação terciária e a emergência de um mercado global para o capital humano avançado" (p. xix), na sua articulação à "emergência de uma miríade de alianças, articulações e parcerias dentro das instituições terciárias, entre instituições diversas e até mesmo expandidas para além do setor da educação terciária" (p. 41).

Todo um capítulo é dedicado ao "enfrentamento dos velhos desafios: a crise persistente da educação terciária nos países em desenvolvimento e em transição" (p. 45). "Um melhor aproveitamento do knowhow tecnológico emergente" (p. 13) é associado ao "acesso a novos produtos e serviços de educação à distância, facilitando o fornecimento de programas qualificados" (p. 180), produzidos nos países desenvolvidos. Nesses termos, é legitimada a existência de um fosso entre dois mundos. O primeiro constituído pelos países centrais é marcado pela derrubada de limites, enquanto o "outro" (formado pelos países capitalistas dependentes) deve aprender a respeitar fronteiras estritas, como "disciplinas e campos congruentes com as oportunidades de inovação emergentes no contexto local" (p. 132, grifo nosso).

2003 - Educação permanente na economia global do conhecimento: desafios para os países em desenvolvimento - quarta e última publicação-chave, endereçada aos países em desenvolvimento e às economias em transição da Europa e da Ásia Central. Na capa, a foto de um grupo de meninos em frente a um computador. Não há meninas, embora o texto enfatize a "desigualdade de gênero no acesso" ( $p$. 14) às tecnologias da informação e da comunicação (doravante TIC). Não são todos negros e é o branco que controla o mouse. Os que estão bem em frente ao computador parecem bastante atentos. Quanto aos outros, não deixam de ter algum acesso à "tecnologia mais moderna" (p. 18).

Acesso é uma palavra repetida mais de 80 vezes, e sua transitividade põe em jogo uma questão substantiva, além das condições da sua realização. As indicações explícitas são: “o conhecimento” (p. 34), a 
expansão de "oportunidades de aprendizagem" (p. 36), ou simplesmente o "acesso à aprendizagem" (p. 20, 45,71 ), como se não se referisse a um processo interno. A seção "Usando a tecnologia para transformar a aprendizagem" propõe uma inversão significativa: "a aprendizagem precisa se tornar mais flexível e diferenciada para permitir mecanismos de distribuição (delivery) alternativos" (p. 65).

O pressuposto básico é: uma vez que as práticas econômicas e sociais foram transformadas, é a vez da aprendizagem: "a emergência da economia global do conhecimento premia a aprendizagem no mundo" (p. 13); e "a emergência de novos fornecedores, oferecendo serviços diferentes de maneiras diferentes, representa uma oportunidade para os países em desenvolvimento" (p. 55).

As emergências listadas no texto (p. 46, 53, 54, $55,100)$ reforçam as já contidas nos anteriores, mas é importante destacar a presença de dois elementos novos. O primeiro está relacionado a um argumento de legitimação: "consenso europeu quanto às equivalências e aos mecanismos de garantia de qualidade (de acordo com o processo de Bolonha)" (p. xxii). O segundo envolve uma palavra-chave da nova formulação: "novos instrumentos para a competência intercultural estão emergindo" (p. 22) (grifo nosso).

Competência, como noção ou princípio de organização curricular, não constitui novidade. Entretanto, ao ser recontextualizada na conexão dos discursos da "globalização" e da "economia do conhecimento", adquire feições diferenciadas: alia à suposta revolução tecnológica os novos imperativos econômicos, viabilizando a educação à distância em escala global.

\section{Revolução, tecnologia, mercado e brecha no discurso das emergências}

Todas as publicações-chave referem-se a uma revolução, mas a primeira e a última o fazem apenas uma vez e de forma diferente. Na de 1994, há a referência negativa à Revolução Cultural da China. Na introdução de 2003, uma única menção sugere que “a” revolução está feita. Nas de 2000 e 2002, uma revolução (da informação ou do conhecimento) é reiteradamente anunciada ou assumida como pressuposto. De qualquer modo, em perspectiva determinista, tem por "causa" as TIC. Como afirma Mattelart (2002), a segunda metade do século XX foi marcada pela crença no poder miraculoso das TIC, de tal modo que "o paradigma tecnoinformacional tornou-se o pivô de um projeto geopolítico que tem como função garantir o rearranjo geoeconômico do planeta em torno dos valores da democracia de mercado e em um mundo unipolar" (p. 139).

As TIC parecem não ser historicamente produzidas e apropriadas em relações sociais concretas. Além disso, "geram" todas as mudanças e emergências decantadas no novo paradigma. Parecem ser recontextualizadas apenas no/pelo mercado, sugerindo mecanismos objetivos como leis aplicáveis a todos. Por sua vez, o posicionamento de entidades denominadas "forças do mercado" como sujeito das formulações serve para esconder e/ou legitimar diversas intervenções: "outras mudanças importantes nos últimos anos são o crescimento das forças do mercado na educação terciária e a emergência de um mercado global para o capital humano de nível avançado" (World Bank, 2002, p. 3) e "as forças do mercado estão assumindo papel cada vez mais importante na educação mundial" (World Bank, 2003, p. 19).

O mercado é posto como único centro de poder e seu funcionamento é tido como confiável, a não ser nos países em desenvolvimento (World Bank, 2000, p. 36), em que é requerida intervenção estatal específica, estabelecida como condição. No "capitalismo do livre mercado", essa é a agência que "requer", "exige", "cria" etc., enquanto a força-tarefa (idem) tende a "acreditar". De fato, a "construção de sociedades do conhecimento" (World Bank, 2002), no discurso da globalização, parece aproximar-se da fé como questão de fundo, na medida da reificação do mercado e da conseqüente ausência de agências e agentes identificáveis. Na ausência dos sujeitos, imperam as construções apassivadas no direcionamento das mudanças: "governo dirigido para/pelos resultados" (World Bank, 2003, p. 105), "necessidades estabelecidas pelo mercado" 
(World Bank, 2000, p. 36), “crescimento econômico determinado pelo conhecimento" (World Bank, 2002, p. 4), e "educação orientada por competências" (World Bank, 2003, p. 28). As ações são atribuídas "a uma conexão muito mais complexa de forças" (World Bank, 2002, p. 84), podendo assumir a forma de "incentivos [...] estrategicamente projetados para pressionar as instituições [de educação terciária] à competição" (World Bank, 2003, p. 91). A trama parece posta a nu, mas, sendo creditada ao "sistema" (idem), sustenta a emergência das "forças do mercado".

Em se tratando da educação superior tornada "terciária", as universidades são apenas uma agência entre uma infinidade de outras: novos fornecedores que "aparecem" (World Bank, 2002, p. xix) e integram "parcerias colaborativas, redes e nichos de excelência", na suposição de que esta seja uma relação entre iguais. À lógica da educação como mercadoria (commodity), nem atributos ou disposições pessoais escapam: a educação terciária "é capaz de encorajar independência e a iniciativa, que são commodities valorizadas na sociedade do conhecimento" (World Bank, 2000, p. 37). Fundada no suposto descentramento da categoria trabalho, essa "nova sociedade" é assumida nos discursos cada vez mais afinados dos organismos internacionais.

Ao referir-se às TIC, a UNESCO menciona o "comércio crescente da educação como commodity", enquanto a Organização Mundial do Comércio (OMC) toma providências para incrementar a prestação do serviço, criando condições favoráveis aos fornecedores pela "remoção dos obstáculos à transmissão dos serviços educacionais para além das fronteiras nacionais, por meios eletrônicos ou físicos" (World Trade Organization, 2000). Na comodificação da linguagem cotidiana, o discurso sobre a educação passa a incorporar processos de cálculo econômico para o sucesso no mercado, assim como todo um vocabulário comercial transplantado [mercado educacional, fornecedores e consumidores de serviços educacionais, loja, entrega (delivery) etc.], ora investido de status acadêmico: "na economia do conhecimento emergente, é cada vez mais importante permitir que um país não ape- nas gere conhecimento novo, mas também se engaje no comércio intelectual e científico com os outros" (World Bank, 2000, p. 42).

A suposta revolução é funcional à articulação dos discursos da "sociedade da informação" e da "globalização" em três sentidos: a) permite uma abordagem "técnico-científica" das desigualdades econômicas entre os países, reduzindo-as a uma lacuna ou divisor digital; b) legitima intervenções para "dar assistência aos países que aspiram a superar a lacuna que os separa dos cientificamente avançados" (World Bank, 2002, p. 25); e c) sustenta o rearranjo geoeconômico do planeta, já que "o espelhamento do potencial de mutação informacional no modelo econômico da globalização selvagem converte as separações em apartheid" (Mattelart, 2002, p. 161, grifo do original).

No discurso do BM (2002, p. 14), é enfatizado "o perigo real do aumento da lacuna digital entre as nações e dentro delas". Para seu "enfrentamento", são utilizadas metáforas como batalha, guerra e forçatarefa. Já para representar o mercado mundial sem fronteiras, o apelo de então foi ao meio ambiente: "a eliminação da barreira dà distância física" (idem, p. 33) em um "horizonte educacional transformado pela globalização e pela revolução das TIC" (idem, p. 65).

A despeito dessa retórica, em indagando o que os países periféricos podem comprar no dito mercado mundial, fica patente o aumento das restrições. Enquanto em 2000 (p. 71) "os países em desenvolvimento também podem se beneficiar muito com instrumental tecnológico para pesquisa de segunda mão mas não obsoleto, que pode ser comprado no mercado mundial", em 2002 (p. $4-5$ e 24) resta "acessar as lojas globais do conhecimento e adaptar este conhecimento para uso local".

Como a relação entre cadeias produtivas complexas, tecnologia e inovação não é sequer cogitada, a principal lição (World Bank, 1994) é a de como perpetuar as desigualdades: pela instituição de "um verdadeiro apartheid educacional planetário" (Leher, 2004, p. 7). 


\section{A materialidade do novo imperialismo}

A ideologia como hegemonia de sentido não está circunscrita ao plano do pensamento. O que faz com que as idéias-chave adquiram performatividade é a congruência dessas disposições de pensamento com a base da vida material, isto é, com a relação de classes. É possível afirmar que as ideologias dominantes em um determinado tempo histórico correspondem às ideologias das classes dominantes. Entretanto, a ideologia é um terreno de lutas. Marx, no Prefácio de 1859, lembra que é por meio da ideologia que os homens tomam consciência do conflito entre as forças produtivas e as relações de produção e lutam para resolvê-lo.

Embora a burguesia capitalista seja dominante há mais de dois séculos, as ideologias que permitiram garantir os imperativos capitalistas não foram imutáveis, pois responderam a desafios provenientes de forças antagônicas que são históricas (Guerra Fria, Guerra Infinita) e organizaram “o consenso social” em contextos muito distintos, como os "Trinta Gloriosos Anos do Capitalismo" ou os anos de "vingança do capital contra o trabalho" (Hobsbawn, 1995).

Como lembra Anderson (2004), após o desmonte da União Soviética as proposições que operam o domínio do capital se transformaram de modo profundo, por meio do neoliberalismo. Nem mesmo na época vitoriana se proclamavam tão clamorosamente as virtudes e necessidades do reino do capital em um contexto de capitalismo desregulado. O neoliberalismo é certamente a ideologia mais abrangente e pretensiosa do último século. Chegou a todos os recantos do planeta, reduzindo à ruína o que parecia sólido e tornando sólido o que parecia se desmanchar. O que há algumas décadas sugeria fortalezas anticapitalistas, como o bloco soviético e a China, hoje operam nos seus termos. Mais do que uma ideologia conjuntural, em termos conceituais foi identificada como o fim da história (Fukuyama, 1992) e, na prática política, como o único caminho possível: "there is no alternative" (Halimi, 2002).

A crise do capitalismo da virada para o século XX parecia devastadora. Lênin e Rosa Luxemburgo propugnaram que o capital somente sobreviria ao seu estágio terminal - imperialista - se houvesse regiões do planeta a serem submetidas aos imperativos capitalistas, pois, nesses territórios, a apropriação do excedente seria tão ampla que o centro do sistema poderia ser reequilibrado. A corrida imperialista, as duas guerras mundiais e as novas formas de domínio econômico das potências hegemônicas deram-lhes razão. O capitalismo não apenas sobreviveu como em muitos aspectos se fortaleceu, produzindo uma nova potência imperial: os Estados Unidos.

Mas o período virtuoso do pós-Segunda Guerra mostrou-se muito menos sólido do que o otimismo do consumo de massa parecia anunciar. A abrupta queda da taxa de lucros da economia mundial, em especial dos Estados Unidos (Duménil \& Lévy, 1996), logo se mostrou uma tendência forte e duradoura. Diante desse cenário, não seria possível utilizar a mesma fórmula de que se valera o capital na crise da virada do século XX, pois, desde os anos de 1970, todos os recantos da terra já se encontravam sob imperativos capitalistas. Os problemas colocados para o capital (para onde se expandir para encontrar melhores condições de recomposição da taxa média de lucro? Como evitar uma crise sistêmica?) foram encaminhados no escopo do novo imperialismo.

Três décadas após o momento de inflexão na taxa média de lucros, é forçoso reconhecer que, apesar de países e regiões terem ido ao default, como México (1995), Brasil (1998), Leste Asiático (1997-1998) e Argentina (2001), o sistema do capital não entrou em colapso (Harvey, 2004; Wood, 2003). Esses autores propugnam que a tese central de Rosa Luxemburgo e Lênin sobre a necessidade permanente de expansão do capital está correta, mas que, na virada do século XX, o capital pôde encontrar outra forma de ampliação que não a puramente territorial. Na ausência de novos territórios de acumulação, o capital estruturou-se para ampliar a expropriação e a exploração do trabalho, em um movimento para dentro de si mesmo, promovendo a "vingança do capital contra o trabalho", por meio da erosão dos direitos sociais, da fragmentação das cadeias produtivas e da "deslocalização" e "reterrito- 
rialização" das etapas das cadeias produtivas, situando nas periferias a produção com baixo valor agregado, intensiva em mão-de-obra, energia e recursos naturais. Com a reprimarização e a montagem de plataformas de exportação de commodities nas periferias, o capital portador de juros ganhou novo fôlego, podendo apropriar-se dos excedentes econômicos em proporção inédita.

A “mão invisível” do mercado não seria capaz de empreender essas transformações sistêmicas. Entre os meios mais importantes para empreender tais mudanças, é possível destacar: a ideologia (neoliberalismo, "globalização", sociedade da informação/economia do conhecimento), as instituições que operam e coordenam as ações imperialistas e o uso da coerção extra-econômica (Guerra Infinita ou doutrina Bush). A conformação desse padrão de acumulação, denominada por Harvey (2004) acumulação por despossessão, não pode ser explicada por fatores isolados. $\mathrm{Na}$ análise de Wood (2003), sobressaem, como determinantes da forma de ser do imperialismo de hoje, a existência de um sistema de Estados e os organismos internacionais.

Para dimensionar a recontextualização pretendida, é preciso colocar em relevo: a) as circunstâncias concretas dos diversos contextos, enfatizando as contradições presentes nos imperativos capitalistas do novo imperialismo; e b) a forma como as condicionalidades do BM são convertidas em práticas políticas.

O agravamento da crise estrutural e a política de ajuste estrutural para implementar o novo imperialismo são as nervuras mais axiais da conjuntura dos anos de 1990, promovendo rearranjos na força relativa das frações burguesas dominantes e também entre os subalternos. Isso significa, em termos de análise da prática política concreta, a consideração do bloco de poder hegemônico no Estado e da correlação de forças entre as classes sociais. Embora o padrão de acumulação esteja sendo implementado principalmente por meios econômicos, a apropriação capitalista requer a coerção extra-econômica do Estado. Os setores dominantes necessitam de uma ordem jurídica e política para garantir a regularidade e a capacidade de predição de que o capital necessita em suas transações cotidianas (Wood, 2003, p. 39). Como os Estados seguem centrais para a acumulação capitalista, a consideração dos vínculos das frações locais da burguesia com os circuitos do capital internacional é imprescindível.

Para que as burguesias internacionalizadas possam atuar por meio de um sistema de Estados constituído por aliados, subordinados e inimigos, são necessários organismos capazes de articular esse sistema e de agir em nome de seu núcleo dirigente (o G-7). Daí a atuação dos organismos internacionais (BM, Fundo Monetário Internacional - FMI, OMC) como intelectuais coletivos e operadores do novo imperialismo.

A agenda do ajuste estrutural do BM foi implementada a partir das condicionalidades que esse organismo pôde impor no contexto da Crise da Dívida de 1982. ${ }^{4} \mathrm{Na}$ condição de avalista dos países que estiveram no epicentro da crise (Argentina, Brasil e México), o BM exigiu "corajosas reformas de ajuste estrutural", como contrapartida ao aval e aos empréstimos. No caso brasileiro, um dos fatores decisivos para explicar a proeminência do capital rentista no bloco de poder foi a renegociação da dívida empreendida no escopo do Plano Brady, concluído em 1994, que converteu os títulos da dívida, que eram nominais, em títulos ao portador. Desde então, o valor do título no mercado, balizado pelo chamado "risco-país", dependeria da avaliação das políticas econômicas pelas financeiras e pelos fluxos e influxos de capital. Na prática, os governos tornaram-se reféns do capital rentista que paulatinamente pôde ampliar sua participação nos excedentes econômicos do país.

Após esse processo, a economia latino-americana era outra. Considerando o saldo entre as importações e as exportações, os produtos primários, os de baixa tecnologia, as manufaturas básicas de recursos naturais e de outras fontes primárias passaram, em

${ }^{4} \mathrm{O}$ poder do $\mathrm{BM}$ decorre de sua força econômica e, principalmente, da sua condição de "fiador" das transações entre os governos e a banca internacional. 
porcentagem, de 58\% em 1994 para 80,3\% em 2003. Mesmo a expansão dos produtos de alta tecnologia nas exportações - 2,25\% em 1994 para 9,25\% em 2003 - é enganosa, pois expressa o fortalecimento das maquilas, tanto no México quanto no Brasil (Arceo \& Basualdo, 2006).

Dessas mudanças resultam dominantes três frações burguesas como o novo bloco de poder no Brasil: o setor financeiro, o agronegócio e o setor exportador de commodities. A esse bloco interessam o ensino fundamental e o treinamento profissional, pelo maior retorno aos investimentos em educação. Afina-se com as estratégias e prioridades educacionais do BM (World Bank, 1995) também no que tange à rejeição do "modelo europeu de universidade", caracterizado pela indissociabilidade de ensino, pesquisa e extensão, e à diversificação das fontes de custeio da educação pública e da diferenciação de instituições, permitindo que o BM encaminhe a sua agenda como sendo a dos setores dominantes locais e vice-versa. Assim, as relações entre a burguesia internacional e as frações locais podem conformar a recontextualização.

De fato, os marcos normativos mais amplos que vêm reconfigurando a educação superior brasileira são fortemente congruentes com os documentos do banco apontados anteriormente. A primeira geração compreende o período de "reformas" da Constituição Federal brasileira, em particular: a emenda constitucional n. 19, de 4 de julho de 1998, que dispõe sobre a reforma administrativa (parte estrutural da reforma do Estado), modificando também o inciso $\mathrm{V}$ do art. 206, e a proposta de emenda constitucional n. 370, que pretendeu alterar o estatuto da autonomia universitária, deslocando-a para o nível infraconstitucional. Parte dos objetivos bancomundialistas já fora obtida na própria Constituição de 1988, em especial no art. 209 (“o ensino é livre à iniciativa privada"), por ação de uma burguesia de serviços em ascensão. A segunda geração corresponde ao processo de elaboração da nova Lei de Diretrizes e Bases da Educação Nacional (LDB, lei n. 9.394/96) e do Plano Nacional de Educação (PNE, lei n. 10.172/01), dispositivos que decididamente incentivam a diferenciação das instituições de ensino superior e abrem caminho para a proliferação de cursos à distância. Finalmente, a terceira geração corresponde a um complexo de medidas que articula avaliação, diretrizes curriculares, competências, empregabilidade, inovação tecnológica, TIC, sociedade da informação/ conhecimento etc., operando a comodificação da educação de modo orgânico com o padrão de acumulação que prevaleceu no país.

\section{Educação superior: do modelo universitário ao terciário}

Dos dez artigos dedicados à educação na Constituição Federal de 1988, apenas um é específico sobre a educação superior; ele dispõe exclusivamente sobre universidade. $\mathrm{O}$ art. 207 a define a partir da indissociabilidade de ensino, pesquisa e extensão, estabelecendo que essas instituições gozam de autonomia didáticocientífica, administrativa e de gestão financeira. $\mathrm{O}$ fato de a Constituição reportar-se apenas às universidades não estava relacionado à exclusividade desse modelo no país, mas à disposição de afirmar a desejabilidade desse modelo, avaliação corroborada pelo art. 218 da carta, que afirma a prioridade do apoio estatal ao desenvolvimento científico e tecnológico do país.

Em 1988, das 871 instituições de ensino superior brasileiras, 87 eram universitárias (31 privadas), totalizando $51 \%$ dos estudantes. As universidades públicas possuíam então $30 \%$ dos estudantes (MEC/ INEP, 2006). Em 2006 (idem; MEC/INEP, 2000) havia um total de 248 instituições públicas e 2.022 privadas (sendo 92 universidades públicas e 86 privadas, não havendo alteração significativa no percentual total de estudantes); o que mudou foi a natureza do que vem a ser uma universidade e a presença empresarial. Entre as privadas, 1.583 eram particulares (assumidamente com fins lucrativos), o setor que mais se fortaleceu nos Governos Cardoso e Lula da Silva: no período 19992002, o número de matrículas das instituições de ensino superior com fins lucrativos cresceu $90 \%$, enquanto, no mesmo período, o crescimento daquelas sem fins lucrativos foi de 31\%. Em 2006, o setor particular era responsável por 55\% das matrículas privadas. 
Considerando as baixas exigências para o credenciamento como universidade, é possível afirmar que a grande maioria dessas instituições não possui pesquisa institucionalizada em diversos campos do saber, o que falseia os resultados. Como o grosso da pesquisa está nas universidades públicas, é possível afirmar que não muito mais do que $22 \%$ dos estudantes (os das públicas, exclusive as municipais) convivem em ambiente de pesquisa.

Outras mudanças aconteceram: surgiram os centros universitários (119 em 2006) que, a despeito do nome, não possuem atividade de pesquisa como determina a Constituição. As instituições isoladas e integradas proliferaram de modo extraordinário, somando 1.765 instituições (Gráfico 1), e as faculdades tecnológicas (não computadas à parte em 1988) somaram 208 instituições em 2006. As instituições com fins lucrativos, que inexistiam no censo de 1988, hoje somam 1.583 instituições (MEC/INEP, 2006) (Gráfico 2).

Esses indicadores comprovam que a proposição geral do BM de diversificação das IES é uma

Gráfico 1: Diferenciação das instituições de ensino superior (IES)

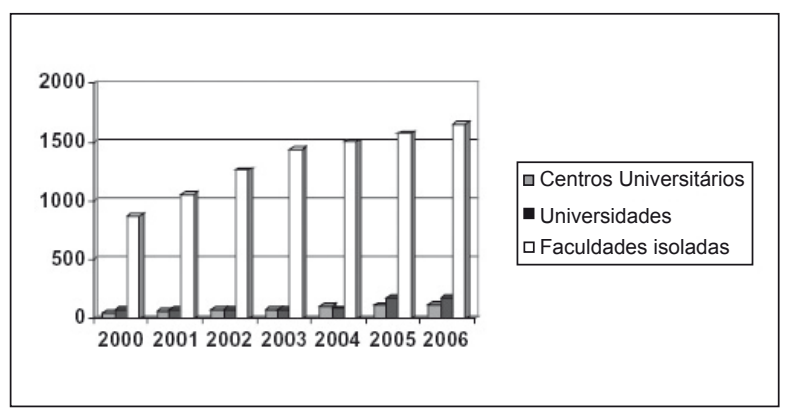

Fonte: Censos da Educação Superior INEP (2000-2006).

Gráfico 2: Expansão das instituições privadas (Brasil: 1999-2006)

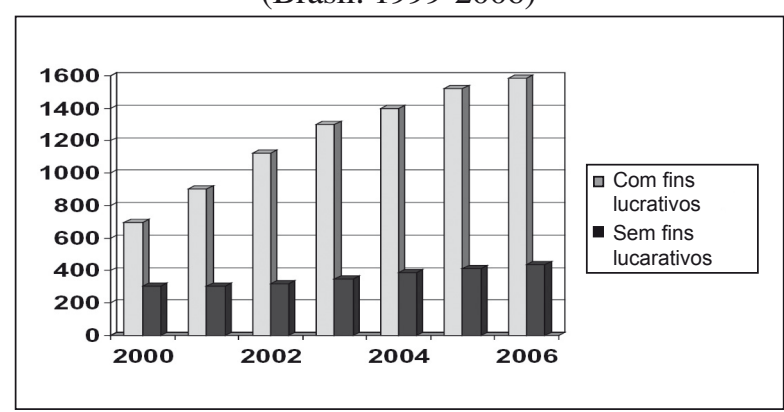

Fonte: Censos da Educação Superior INEP (2000-2006). realidade no país. Mesmo que as universidades ainda mantenham mais da metade dos estudantes, é forçoso reconhecer que somente cerca de um quinto dos estudantes está em instituições com pesquisa mais ou menos institucionalizada. A expansão abrupta das universidades deve-se ao crescimento das privadas, que estão acelerando sua conversão em universidades, em virtude da flexibilização dos critérios para criação e transformação, bem como das prerrogativas que essas instituições possuem. Outro aspecto a salientar, tal como previsto no documento do BM de 2000, é que o empresariamento do setor está sendo drasticamente acelerado, com o crescimento das entidades com fins lucrativos (particulares) (Gráfico 2).

Estão em curso ainda outras mudanças congruentes com a agenda do BM, como a educação à distância, que vive um verdadeiro boom neste início dos anos 2000. O BM, a UNESCO e a OMC sustentam seu suposto caráter revolucionário. Ao mesmo tempo, os governos da América Latina e do Brasil em particular ${ }^{5}$ apressam sua regulamentação com vistas à institucionalização dessa "modalidade" de curso. ${ }^{6}$

${ }^{5}$ O projeto de lei n. 7.200/06 e o decreto n. 5.622, de 19 de dezembro de 2005, que regulamentam a educação à distância, antecipam a aplicação dos termos da OMC mesmo sem a efetivação desse tratado de livre comércio. O projeto de lei n. 7.200 concebe a educação à distância como modalidade de ensino, permitindo seu uso em todos os cursos de graduação, mestrado e doutorado (admitindo mestrados sem dissertações e doutorados sem tese) e autoriza o reconhecimento desses de diplomas obtidos no comércio transfronteiriço pelas universidades privadas. Propugna a admissibilidade da entrada de capital estrangeiro nas instituições privadas, embora restrita a $30 \%$, viabilizando associações entre empresas nacionais e estrangeiras. Assim, a multinacional Apollo poderá ofertar cursos de mestrado e doutorado à distância e a Faculdade Pitágoras, instituição a ela associada, reconhecerá o diploma virtual com validade nacional e em todo o Mercado Comum do Sul (MERCOSUL).

${ }^{6}$ Como afirma Barreto (2006), a educação à distância é a única modalidade que não é nomeada em função da clientela e/ou do nível de ensino, mas do seu modus operandi. Nesses termos, permite que as análises estejam centradas na sua dimensão operacional. Propõe 
Centenas de novos cursos à distância são criados em ritmo meteórico, em uma desenfreada corrida por novas oportunidades de negócios.

Tabela 1: Expansão do número de ingressantes/ano em cursos de graduação à distância

\begin{tabular}{|c|c|c|c|}
\hline & $\begin{array}{c}\text { Ingressantes nas } \\
\text { IES públicas }\end{array}$ & $\begin{array}{c}\text { Ingressantes } \\
\text { nas IES privadas }\end{array}$ & TOTAL \\
\hline 2002 & & & 20.685 \\
\hline 2004 & 19.993 & 5.013 & 25.006 \\
\hline 2005 & 54.176 & 117.210 & 171.386 \\
\hline 2006 & & & 212.246 \\
\hline
\end{tabular}

Fonte: INEP. Censos da Educação Superior (2002, 2004, 2005, 2006)

* Nos anos de 2002 e 2006, não foi feita a consolidação dos ingressantes nas IES públicas e privadas.

Em alguns países, universidades virtuais são criadas como uma "alternativa realista" capaz de massificar a graduação e, cada vez mais, a pós-graduação. Reconhecendo o atraso do país no nível "terciário" de educação, o que configura um obstáculo para a entrada no seleto grupo das "economias do conhecimento", o governo brasileiro criou a Universidade Aberta do Brasil (UAB), por meio do decreto n. 5.800, de 8 de junho de 2006. A rigor, trata-se de uma fundação de direito privado que, por meio de consórcios, organiza cursos à distância, em especial para formar (e, principalmente, certificar) centenas de milhares de profissionais engajados na "sociedade do conhecimento". Essa universidade está consignada na forma de um consórcio entre estatais, prefeituras, universidades públicas e privadas, sob a coordenação de um conselho gestor constituído, entre outras entidades, pela Confederação Nacional da Indústria (CNI). A presença empresarial é concebida como crucial para que a educação terciária seja considerada pertinente (ao mercado). Por sua vez, a presença da Coordenação de Aperfeiçoamento de Pessoal de Nível Superior (CAPES) pode contribuir para que essa educação comodificada circule no mercado com um "selo de qualidade".

a objetivação da educação à distância como estratégia política, de modo que privilegie as questões substantivas antes e para além dos aspectos operacionais.
É essa modalidade que serve também de cavalo de Tróia para modernizar as tradicionais e conservadoras universidades públicas, que seguem ainda como referências de qualidade. Recente minuta de decreto governamental (Plano Universidade Nova de Reestruturação e Expansão das Universidades Federais Brasileiras, de março de 2007) explicitou a questão de modo meridianamente claro: a atual graduação seria partida em duas etapas, a primeira, minimalista, nos moldes dos community colleges - cursos genéricos de dois ou três anos, podendo ou não ser vocacionais -, e a segunda, reservada apenas para os especialmente talentosos, de natureza profissionalizante. Dependendo do "talento", o estudante pode cursar mais um ano e licenciar-se para o magistério, nos moldes das criticadas licenciaturas curtas. Estudantes especialmente talentosos poderiam cursar as carreiras mais prestigiosas, de quatro ou cinco anos adicionais, ou mesmo dirigir-se à pós-graduação stricto sensu. Nos termos da minuta do referido decreto, os cursos genéricos massificados - teriam de ser parcialmente à distância, valendo-se do consórcio UAB.

$\mathrm{O}$ crescimento exponencial das graduações à distância, o esvaziamento do conceito de universidade e a imensa proliferação de diversas instituições radicalmente distintas do "modelo europeu" são partes desse processo. Quando o Governo Lula da Silva teve início, $10 \%$ das matrículas do ensino superior já eram de cursos de curta duração; em 2008, o total desses estudantes deve alcançar $20 \%$ conforme os debates que circulam na Associação Brasileira das Mantenedoras da Educação Superior (ABMES, 2005). Esse modelo, conforme o estudo, já está em aberta discussão nas universidades federais, por meio do projeto Universidade Nova e pelo Programa de Reestruturação das Universidades Federais e está sendo implementado por meio dos cursos superiores de tecnologia, que passaram de pouco mais de mil em 2003 para 3,5 mil em 2006, conforme o censo do INEP, 2006.

Examinando os estágios que levaram a um novo marco jurídico-normativo da educação superior brasileira no período 1995-2006 - reformas constitucionais, leis gerais da educação (LDB/PNE) e 
todo um conjunto de medidas que permitem a plena operacionalização do novo ordenamento -, é possível identificar que a gestão Cardoso (1995-1998, 19992002) avançou no macro reordenamento da educação brasileira, enquanto o primeiro governo de Lula da Silva (2003-2006) logrou avanços na definição de instrumentos operacionais.

O presente estudo propugna que ambos os governos desenvolveram uma agenda coerente e consistente com a do BM. Contudo, com base no conceito de recontextualização (Fairclough, 2006), rejeita a hipótese de que os governos em questão tenham simplesmente seguido sua cartilha, em um movimento de atender às condicionalidades postas direta e simplesmente. As condições de produção da agenda nacional incluem circunstâncias e formulações concretas. Incluem as mediações constitutivas das lutas por hegemonia. A partir de Wood (2003), foi focalizado o modo como as frações burguesas locais interagem com as frações hegemônicas, tanto no mundo dos negócios e das finanças como, especialmente, no sistema de Estados que opera o imperialismo.

No contexto educacional, a privatização, a mercantilização e a comodificação crescentes da educação superior foram demandas concretas de uma fração burguesa local, que já possuía sólidos negócios na área. Essa fração, por sua força parlamentar e junto ao bloco dominante, obteve concessões extremamente benéficas para seus negócios: isenções tributárias mesmo para as instituições particulares (com fins lucrativos) estabelecidas pelo Programa Universidade para Todos (PROUNI) e incentivo permanente à diferenciação das instituições e modalidades de educação superior, naturalizando a sua conversão em educação terciária.

Com a diferenciação de instituições de ensino superior e a descaracterização do conceito de universidade, já que a grande maioria das universidades privadas não possui pesquisa institucionalizada, a educação à distância pode servir de catalisador para acelerar a reconfiguração das universidades públicas, iniciada em meados dos anos de 1990: também estas se metamorfoseariam em instituições terciárias. Assim, ignorando a história, futuros documentos do BM poderão afirmar que em países como o Brasil emergiram universidades minimalistas, capazes de certificar milhares de jovens para a economia do conhecimento e para um mercado de trabalho desregulamentado e flexível, como querem os representantes desse ideário.

\section{Referências bibliográficas}

ABMES - Associação Brasileira das Mantenedoras da Educação Superior. Seminários de 2005. 2005. Disponível em: <http://www. abmes.org.br/Seminarios/2005.asp>. Acesso em: 10 nov. 2007.

ANDERSON, Perry. Considerações sobre o marxismo ocidental. São Paulo: Boitempo, 2004.

ARCEO, Eduardo; BASUALDO, Enrique M. (Orgs.). Neoliberalismo y sectores dominantes. Buenos Aires: CLACSO, 2006.

BANCO MUNDIAL. Do confronto à colaboração: relações entre a sociedade civil, o governo e o Banco Mundial no Brasil. 2000. Disponível em: <http://www-wds.worldbank.org/servlet/main?m enuPK=64187510\&pagePK=64193027\&piPK=64187937\&theSi tePK=523679\&entityID=000012009_20040325125441 >. Acesso em: 24 set. 2008

BARRETO, Raquel Goulart. Formação de professores, tecnologias e linguagens: mapeando velhos e novos (des)encontros. São Paulo: Loyola, 2002.

. Política de educação à distância: a flexibilização estratégica. In: LOPES, Alice Casemiro; MACEDO, Elizabeth (Orgs.). Políticas de currículo em múltiplos contextos. São Paulo: Cortez, 2006. p. 187-204.

.; LEHER, Roberto. Trabalho docente e as reformas neoliberais. In: OLIVEIRA, D. A. (Org.). Reformas educacionais na América Latina e os trabalhadores docentes. Belo Horizonte: Autêntica, 2003. p. 39-60.

BOURDIEU, Pierre; WACQUANT, Loic. NewLiberalSpeak: notes on the new planetary vulgate. Radical Philosophy, n. 105, p. 2-5, 2001. DUMÉNIL, Gérard; LÉVY, Dominique. La dynamique du capital: um siècle d'économie américaine. Paris: Presses Universitaires de France, 1996.

FAIRCLOUGH, Norman. Discurso e mudança social. Brasília: Editora da UnB, 2001.

Blair's contribution to elaborating a new "doctrine of international community". Journal of Language and Politics, v. 4, n. 1, p. 41-63, 2005. 
Do discurso e das condicionalidades do Banco Mundial, a educação superior "emerge" terciária

Language and globalization. London: Routledge,

2006.

FUKUYAMA, Francis. O fim da história e o último homem. Rio de Janeiro: Rocco, 1992.

HALIMI, Serge. How neo-liberalism took over the world. There is an alternative. Le Monde Diplomatique, English Edition, jan. 2002.

Disponível em <http://mondediplo.com/2002/01/11alternative>. Acesso em: 28 maio 2007.

HARVEY, David. O novo imperialismo. São Paulo: Loyola, 2004. HOBSBAWN, Eric. Era dos extremos, o breve século XX. São Paulo: Companhia das Letras, 1995.

LEHER, Roberto. A new lord of education? World Bank policy for peripheral capitalism. Journal for Critical Education Policy Studies, 2004. Disponível em: <http://www.jceps.com/index. php?pageID=home\&issueID=3>. Acesso em: 15 abr. 2007.

MATTELART, Armand. História da sociedade da informação. São Paulo: Loyola, 2002.

MEC/INEP. Evolução do ensino superior: graduação 1980-1998. Brasília: MEC/INEP, 2000. Disponível em: <http://www.inep. gov.br/superior/censosuperior/evolucao/evolucao.htm $>$. Acesso em: 18 maio 2008.

Sinopses estatísticas da educação superior: gra-

duação. 2006. Disponível em: <http://www.inep.gov.br/superior/ censosuperior/sinopse>. Acesso em: 13 jun. 2008.

UNESCO. ICT in education. Disponível em: <http://portal.unesco. org/ci/en/ev.php-URL_ID=2929\&URL_DO=DO_TOPIC\&URL_ SECTION=201.html >. Acesso em: 30 abr. 2007.

WOOD, Elen Meiksins. El imperio del capital. Espanha: El Viejo Topo, 2003.

WORLD BANK. Higher education: the lessons of experience. 1994. Disponível em: <http://siteresources.worldbank.org/EDUCATION/ Resources/278200-1099079877269/547664-1099079956815/ HigherEd_lessons_En.pdf>. Acesso em: 23 abr. 2007.

Priorities and strategies for education: a World Bank review. Washington: BIRD/World Bank, 1995.

Higher education in developing countries: peril and

promise. 2000. Disponível em: <http://siteresources.worldbank. org/EDUCATION/Resources/278200-1099079877269/5476641099079956815/peril_promise_en.pdf>. Acesso em: 15 abr. 2007.

Constructing knowledge societies: new challenges for tertiary education. 2002. Disponível em: <http://web.worldbank.org/ WBSITE/EXTERNAL/TOPICS/EXTEDUCATION/0,,contentMD
K:20283509 isCURL:Y menuPK:617592 pagePK:148956 piPK: 216618 theSitePK:282386,00.html>. Acesso em: 23 abr. 2007. . Lifelong learning in the global knowledge economy: challenges for developing countries. 2003. Disponível em: <http:// web.worldbank.org/WBSITE/EXTERNAL/TOPICS/EXTEDUC ATION/0,,contentMDK:20283504 isCURL:Y menuPK:61759 2 pagePK:148956 piPK:216618 theSitePK:282386,00.html>. Acesso em: 12 maio 2007.

WORLD TRADE ORGANIZATION. S/CSS/W/23. 2000. Disponível em: <http://www.unesco.org/education/studyingabroad/highlights/global_forum/gats_he/us.pdf>. Acesso em: 30 abr. 2007.

RAQUEL GOULART BARRETO, doutora em educação pela Universidade Federal do Rio de Janeiro (UFRJ), é professora da Faculdade de Educação da Universidade do Estado do Rio de Janeiro (UERJ), na qual coordena o grupo de pesquisa Educação e Comunicação, com as pesquisas: "As tecnologias da informação e da comunicação nas políticas de formação de professores: os sentidos da reconfiguração de trabalho-formação docente" (UERJProciência); "Tecnologias na educação: sentido hegemônico e condições de produção" (Conselho Nacional de Desenvolvimento Científico e Tecnológico - CNPq); e "A leitura no aperfeiçoamento do ensino: uma proposta de pesquisa participante" (Fundação de Amparo à Pesquisa do Estado do Rio de Janeiro - FAPERJ). Publicações recentes: como organizadora, Tecnologias educacionais e educação à distância: avaliando políticas e práticas (2. ed. Rio de Janeiro: Quartet, 2003); “Tecnologia e educação: trabalho e formação docente" (Educação e Sociedade, n. 89, p. 1.181-1.201, set./dez. 2004); "A presença das tecnologias" (In: FERRAÇO, Carlos Eduardo (Org.). Cotidiano escolar, formação de professores (as) e currículo. São Paulo: Cortez, 2005. p. 141-157); "Política de educação à distância: a flexibilização estratégica" (In: LOPES, Alice Casemiro; MACEDO, Elizabeth (Orgs.). Políticas de currículo em múltiplos contextos. São Paulo: Cortez, 2006. p. 187-204); "Educação à distância e formação de professores para a escola básica” (In: SCHWARTZ, Cleonara Maria et al. (Orgs.). Desafios da educação básica: a pesquisa em educação. Vitória: EDUFES, 2007.p.167-176).E-mail: raquel@uol.com.br

ROBERTO LEHER, doutor em educação pela Universidade de São Paulo (USP), é professor da Faculdade de Educação da Universidade Federal do Rio de Janeiro (UFRJ). Publicações recentes: "Brazilian education, dependent capitalism and the 
World Bank" (In: HILL, Dave; KUMAR, Ravi (Orgs.). Global neoliberalism and education and its consequences. New York: Routledge, 2008); “A problemática da universidade 25 anos após a crise da dívida" (Universidade e Sociedade, v. 39, p. 9-15, 2007); "Florestan Fernandes e a universidade no capitalismo dependente" (In: FÁVERO, Osmar (Org.). Democracia e educação em Florestan Fernandes. Campinas: Autores Associados, 2005. p. 211-245); "A new lord of education? World Bank policy for peripheral capitalism" (Journal For Critical Education Policy Studies, London, v. 2, p. 10-25, 2004); "Para silenciar os campi" (Educação \& Sociedade, São Paulo/Campinas, v. 25, n. 88, p. 867-892, 2004). No período 2004-2007 coordenou o grupo de trabalho Universidad y Sociedad, do Conselho Latino-Americano de Ciências Sociais (CLACSO). Coordena as seguintes pesquisas: "Ajuste estrutural, capitalismo dependente e universidade periférica na América Latina”; "Observatório Social da América Latina"; e "Outro Brasil - análise da conjuntura brasileira", financiado pela Fundação Rosa Luxemburgo da Alemanha. E-mail: rleher@uol.com.br

Recebido em janeiro de 2008

Aprovado em junho de 2008 


\section{Resumos/Abstracts/Resumens}

Raquel Goulart Barreto

Roberto Leher

Do discurso e das condicionalidades

do Banco Mundial, a educação superior "emerge" terciária

$\mathrm{O}$ artigo discute as mudanças na educação superior produzidas pela recontextualização do discurso do Banco Mundial no Brasil, considerando os modos pelos quais as condicionalidades estabelecidas têm sido convertidas em práticas políticas. Está estruturado em duas partes. A primeira, centrada na materialidade do discurso, analisa as publicações que o banco identifica como chave para a educação superior, a partir das marcas constitutivas do "discurso das emergências". A segunda parte aborda a materialidade do novo imperialismo, explicita as contradições que o sustentam e focaliza as condições de produção do deslocamento do modelo universitário para o terciário.

Palavras-chave: discurso; novo imperialismo; recontextualização; educação superior
From the discourse and conditionalities of the World Bank, higher education "emerges" tertiary This article discusses changes in higher education produced by the recontextualization of the World Bank's discourse in Brazil, considering the ways in which "governance-related conditionalities" have been converted into political practices. It consists of two parts. The first one, centred on discourse as a material form of ideology, analyzes the "key publications" related to higher education, based on the features of what can be called a "discourse of emergences". The second part approaches the material dimension of the new imperialism, elicits its fundamental contradictions and focuses the conditions of production of shifting from the university-based model to the tertiary one.

Key words: discourse; new imperialism; recontextualization; higher education

Del discurso y de las condiciones del Banco Mundial, la educación superior "emerge" terciaria
El artículo discute los cambios en la educación superior producidos por la recontextualización del discurso del Banco Mundial en Brasil, considerando los modos por los cuales las condiciones establecidas han sido convertidas en prácticas políticas. Está estructurado en dos partes. La primera, centrada en la materialidad del discurso, analiza las publicaciones que el banco identifica como clave para la educación superior, a partir de las marcas designadas del "discurso de las emergencias". La segunda parte aborda la materialidad del nuevo imperialismo, explícita las contradicciones que lo sustentan y enfoca las condiciones de producción del dislocamiento del modelo universitario para el terciario.

Palabras clave: discurso; nuevo imperialismo; recontextualización; educación superior

Sebastián Donoso Díaz

$O$ aperfeiçamento docente no Chile (1990-2007): Estado versus mercado? 